\title{
Cork Re-Wall
}

\author{
Computational Methods of Automatic Generation and Digital Fabrication of Cork Partition Walls for Building Renovation
}

\author{
- Filipe Brandão \\ Portugal \\ filipejsbrandao@hotmail.com \\ Alexandra Paio \\ ISCTE-IUL and Vitruvius FABLAB/ISTAR-IUL, \\ Portugal \\ alexandra.paio@iscte.pt
}

\author{
- José Pedro Sousa \\ University of Porto, Faculty of Architecture + \\ DFL/CEAU, Portugal \\ jsousa@arq.up.pt \\ - Vasco Rato \\ ISCTE-IUL, and Vitruvius FABLAB/ISTAR-IUL \\ Portugal \\ vasco.rato@iscte.pt
}

\begin{abstract}
Developments in computational design methods and their integration with digital fabrication processes are ushering a customized fabrication paradigm. This paradigm is particularly suited to renovation of old buildings built with traditional construction techniques, a diversified corpus in which interventions are surgical and unique, and where partition walls play the central role. Insulation Cork Board and OSB, natural and renewable materials, can have an important role in a material system that responds to this context. Cork re-Wall is a parametrically modelled construction system and a file-to-factory digital process to generate high quality custom solutions to respond to diverse renovation design challenges.
\end{abstract}

Keywords: Cork, Wood Frame, Digital Fabrication, Renovation, Parametric Design

\section{Introduction}

This paper describes the research done during the Advanced Studies Course in Digital Architecture (CEAAD), a joint initiative between ISCTE-IUL and FAUP.

The construction of new buildings in Portugal has dramatically shrunk in the last few years, while the renovation of old buildings within cities historic centers gained traction, after decades of neglect. This renewed interest was fostered mainly by changes in legislation, municipal investment in public spaces, a general drop in property prices and increased private investment driven by tourism. In 2001, INE (National Statistics Institute) estimated that over 50\% of the buildings in Lisbon and Porto were in need of renovation in varying degrees. A significant part of these old buildings are concentrated on historic quarters and range from the 18th to the beginning of the 20th century(Freitas, 2012). They are built of stone masonry façades and party walls, wood beam floors, wood trusses and wood frame partition walls. Both the stone and wood partition walls were gypsum plastered, while often the main façade would be covered with ceramic tiles. In renovation interventions, the main focus is the reorganization of the interior. Façades, wood floors and roofs are either repaired or kept in the original condition.

The increased demand of refurbished buildings is frequently addressed with modern construction techniques and materials, which are often strange to the original construction logic of the building. This happens both because modern wood frame partition wall is not competitive and traditional techniques have either become too expensive or craftsmen are no longer available. A definite need exists for approaches that better integrate the specific requirements of renovation projects with mass production. Nonetheless, building renovation design and construction are piecemeal by nature and as such not prone to standardized construction methods.

Developments in computational design methods and their integration with digital fabrication processes allow us to think of a customized construction paradigm (Naboni \& Paoletti, 2015). This new process strategy is especially suited to the renovation of buildings built with traditional construction techniques, a diversified corpus in which the interventions are surgical and non-standard. Insulation Cork Board (ICB) is a natural and renewable material which maintains most of the characteristics of raw cork: lightness, buoyancy, viscoelasticity, and improves some like low heat and sound conductivity and acts as a fire retardant (Fortes, Rosa, \& Pereira, 2003; L Gil, 1998; Pereira, 2007). Moreover, as a result of its production process, which originates big size blocks, it's better suited to architectural applications and, as Sousa (2010) work demonstrates, appropriate for customization processes with CNC technologies (Figure 1). Wood derivates like OSB (Oriented Strand Board) and plywood are also natural and 
renewable materials which in turn have complementary mechanical properties to ICB, namely, higher mechanical strength. In this context, we foresee that a file-to-factory digital process (Varela, Paio, \& Sousa, 2014)will have several advantages: higher quality and speed without sacrificing scope or increasing cost (Kieran \& Timberlake, 2003).

The goal of this work is to develop a partition wall system based on cork material and wood derivates, which can be customizable through an integrated digital design and fabrication process. Named as Cork re-Wall, the system aims at targeting the building renovation industry. The parametric partition wall must address the need of a process to integrate infrastructural and constructive systems in design, fabrication and assembly. It must also be a more symbiotic and sustainable solution to renovation than current methods, improving also on the ease and quickness of assembly process.

This paper is divided into three sections. First, the context of this investigation is outlined. Then the objectives and the methodology are defined. Lastly, the two first development cycles are briefly described and the last one is explained in more detail.

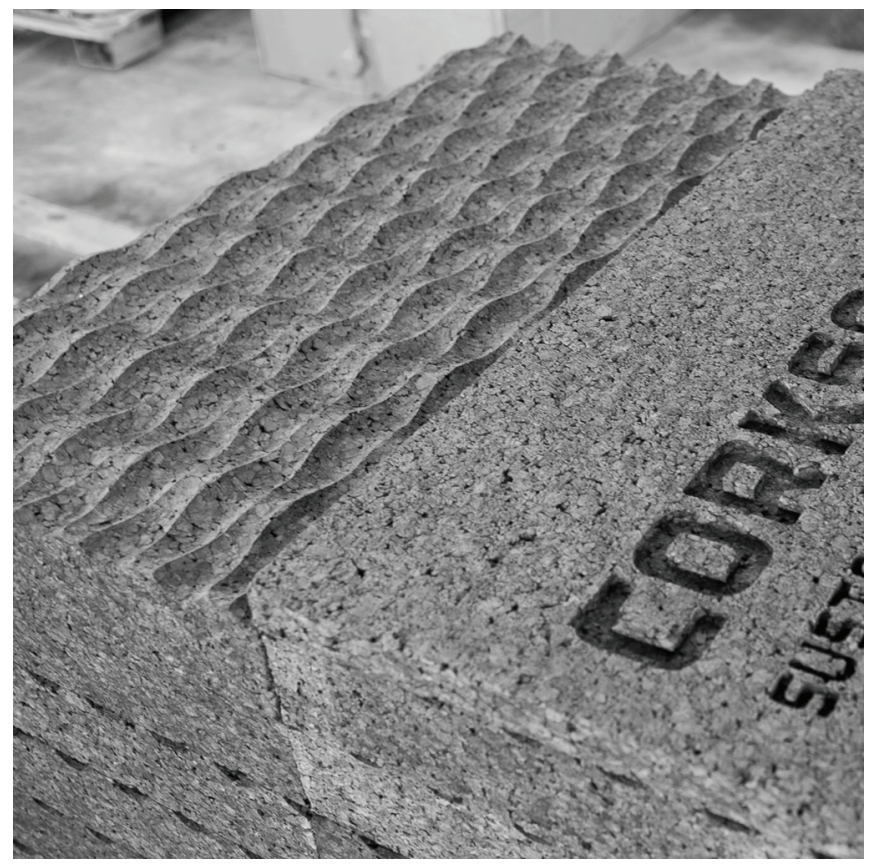

Figure 1: CNC milled insulation cork boards.

\section{Renovation}

In this work, renovation is understood as a set of interventions on built heritage pursued with the aim of improving its safety, comfort and usefulness which nonetheless respect its architecture, typology and constructive system. The partition wall that was devised aims to reinstate the use or traditional materials in the renovation of old buildings, implementing generative design and digital fabrication to overcome the loss of traditional building techniques and craftsmen. This solution doesn't preclude the adoption of an adequate design practice to the context at hand, which correctly evaluates the structural and spacial viability of the building and weights the need to intervene according to the same principles of sustainability that underpin the development of this solution.

Traditional partition wall construction systems were briefly studied in order to understand their benefits and shortcomings, both in terms of building process and performance. Several wood frame partition wall types coexist, yet the most common in the North of Portugal is the tabique simples - a wood frame partition wall reinforced with wood boards that form a surface for laths and plaster (Figure 2). It's clear that they are not viable as contemporary construction process mostly because of the amount of manual labor spent on onsite assembly, lack of wall cavities for infrastructure and bad acoustic insulation.

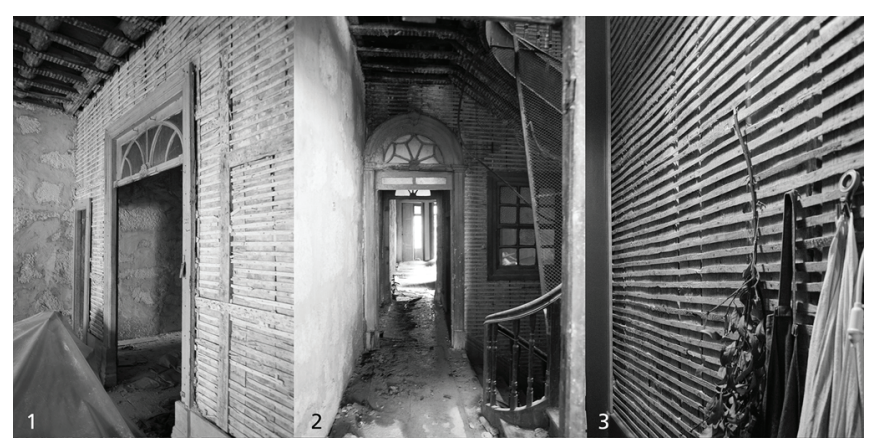

Figure 2: Tabique simples -traditional wood frame partition walls (1 to 3 )

\section{Material}

Cork is the oak tree bark extracted every 9-12 years from a tree that is at least 30 years old and as an average life of 200 years. The first two extractions don't produce first quality cork used for cork stoppers, they are instead used for granulates and aggregates like ICB. Yet the main raw material of ICB are granulates of the bark extracted from pruned branches of the oak tree - falca. The extraction of cork from the oak tree doesn't kill it; it is precisely this exploration that is responsible for the maintenance of high conservation value cork oak "Montado". forest (Bugalho, Caldeira, Pereira, Aronson, \& Pausas, 2011)

ICB is the outcome of a natural agglomeration process of cork granulates when subject to temperature of $300-370^{\circ} \mathrm{C}$ and a pressure of $30-60 \mathrm{kPa}$ inside an autoclave. There are no additives to the process and the binding agent is suberin, the natural resin of cork. Furthermore the energy used in the industrial process is generated from burning the residues of the processing and granulation of the raw material to produce steam. This industrial process produces blocks of 1000x500x320mm that are then sawn into $1000 \times 500$ boards with varying widths. It's mainly used as thermal and acoustic insulation in building roofs, walls or floors but also as antivibration insulation for machines. Heat processing of cork improves its thermal and acoustic behavior but on the other hand worsens some mechanical properties like Young's Modulus, tensile or compressive strength. Research has been 
conducted with the aim of improving these properties of ICB through a densification process (L. M. C. C. Gil, 1996) or by combining ICB with plywood to create a composite panel (Lakreb, Bezzazi, \& Pereira, 2015). Other paths of investigation and application have risen from other properties of cork, such as its durability and resilience to sun exposure, its texture and odor. These properties set it aside from other types of insulation materials and made way for architectural solutions such as Portugal's Pavilion in Hannover, designed by Alvaro Siza, and Sousa's (2010) investigation on the use of CNC technologies for customization of form, texture and size of cork boards.

\section{Digital Processes}

Digital tools are increasingly becoming a common part of the design process (Clayton, 1995). The evolution and proliferation of parametric or algorithmic design software's and the increasing use of generative design processes in architecture are concurring to ease the access to digital production (Naboni \& Paoletti, 2015). On the other hand, programming as a tool and skill is increasingly democratized, as a result of more accessible programming languages (Blikstein, 2013). Furthermore, digital fabrication tools like CNC routers or 3D printers are becoming widespread both because of reducing costs and of initiatives like Fab Lab or the Global Village Construction Set.

\section{Hypothesis}

Cork Re-Wall parametric partition wall was developed to be deployed in building renovation. The offer of ICB products that meet the specific requirements of building renovation is already significant. Yet ICB use for partition walls is very scarce mainly because of its cost compared to other insulation materials. This work aims to explore the use of ICB in partition walls rethinking the traditional partition wall found in historic buildings.

Renovation has a specific set of needs that differ from new building construction. Foremost, renovation acts upon built heritage, which preserves in varying degrees. The construction process usually begins with an intervention on the roof and progresses inward. Moreover, these buildings are located in slender plots, in neighborhoods with scanty streets. Lastly, existing wooden beam floors aren't capable of withstanding heavy partition ceramic brick walls and dry building processes are more adequate. These conditions limit the dimensions of materials arriving on site, the way the building process is carried out and the type of materials used.

Two sets of problems were identified on the analysis of selected case studies of building renovation in Porto:
Issues arising from the need to adapt existing typologies to contemporary living standards, stemming from client wishes or imposed by current building codes; common building pathologies of old buildings or pathologies caused by lack of maintenance or bad interventions. The first set of problems is associated with changes in use, subdivision of buildings into smaller independent units or the need to move the existing bathrooms from the backyard façade to the interior of the building. These needs bring about several problems, most notably problems of ventilation and acoustic insulation. The second set of problems can arise from lack of maintenance but can also stem from interventions with incompatible building techniques, heavier and mostly adapted to new buildings. These inadequate interventions can cause deformations on floors or overloading of stone masonry party walls or façades.

\section{Objectives}

The best practices of renovation of these old buildings have adopted light steel frame (LST) partition walls. These are light and cost effective solutions that address most of the identified problems, but have high EE (Embedded Energy) and EC (Embedded Carbon) mostly because of the steel frame.

From the analysis of renovation case studies and traditional partition wall systems, but also taking into account LST partition wall advantages, a group of requirements was derived:

- Wall thickness that is adjustable

- Adequate airborne sound insulation

- Dampening impact sound transmission

- Flexibility in finishing

- Quick and easy assembly

- Lightness

- Dry construction

- In-wall cavities for infrastructure

- Reusable and renewable materials

- Low cost

ICB easy meets most of these requirements. It's a renewable and reusable material, obtained without damaging the tree. It is carbon neutral and its extraction increases the production of cork by 250-400\% (Luís Gil, 2014) thus increasing $\mathrm{CO} 2$ sequestration. It also has a high level of Carbon content (L Gil, Marreiros, \& Silva, 2011) and a long life span (Luís Gil \& Silva, 2011). Wood shares some of these advantages if it's obtained from responsibly managed forests and more importantly is a material that is already present in these buildings. Wood derivates, like plywood or OSB, are less environmentally friendly mainly due to the industrial processes and the glues used. They are nonetheless less impactful than galvanized steel (Table 3). Lastly, access to CNC processing for wood is far more widespread and cheaper than 


\begin{tabular}{|c|c|c|c|c|c|c|c|c|}
\hline Materials & $\begin{array}{l}\text { Density } \\
(\mathrm{Kg} / \mathrm{m} 3)\end{array}$ & $\begin{array}{c}\mathrm{EEu} \\
(\mathrm{MJ} / \mathrm{Kg})\end{array}$ & $\begin{array}{c}\mathrm{ECu} \\
(\mathrm{KgCO} 2 \mathrm{e} / \\
\mathrm{Kg})\end{array}$ & $\begin{array}{l}\text { Thickness } \\
(\mathrm{m})\end{array}$ & $\begin{array}{c}\text { EEs } \\
(\mathrm{MJ} / \mathrm{m} 2)\end{array}$ & $\begin{array}{c}\mathrm{ECs} \\
(\mathrm{KgCO} 2 / \\
\mathrm{m} 2)\end{array}$ & $\begin{array}{c}\mathrm{EE} \\
(\mathrm{MJ} / \mathrm{m})\end{array}$ & $\begin{array}{c}\mathrm{EC} \\
(\mathrm{Kg}- \\
\mathrm{CO} 2 / \mathrm{m})\end{array}$ \\
\hline Plasterboard & 800 & 6,8 & 0,39 & 0,015 & 81,00 & 4,680 & & \\
\hline $\begin{array}{l}\text { M90 } \\
\text { Galvanized } \\
\text { Steel profile }\end{array}$ & 7800 & 27,1 & 2,03 & 0,0006 & & & 22,131 & 1,658 \\
\hline $\begin{array}{l}\text { M70 } \\
\text { Galvanized } \\
\text { Steel profile }\end{array}$ & 7800 & 27,1 & 2,03 & 0,0006 & & & 19,785 & 1,482 \\
\hline $\begin{array}{l}\text { M46 } \\
\text { Galvanized } \\
\text { Steel profile }\end{array}$ & 7800 & 27,1 & 2,03 & 0,0006 & & & 16,741 & 1,254 \\
\hline Mineral wool & 70 & 16,6 & 1,28 & 0,060 & 69,72 & 5,376 & & \\
\hline ICB & 140 & 4,0 & 0,19 & 0,060 & 33,60 & 1,596 & & \\
\hline OSB & 640 & 15,0 & 0,99 & 0,015 & 144,00 & 9,504 & 17,280 & 1,140 \\
\hline Plywood & 640 & 15,0 & 1,10 & 0,012 & 115,20 & 8,448 & & \\
\hline
\end{tabular}

Table 3: Material properties and Cradle to Gate EC / EE values obtained from the Inventory of Carbon and Energy (Hammond \& Jones, 2006).

for steel.

\section{Methodology}

Three projects of building renovation were selected as case studies. They differ in building typology and in design process but are all located in Porto.

The investigation was divided into three areas: Design, Material and Production. In Design, the subdivision grammars and rules were defined and tested for its adequacy to the context of the design problem. The ultimate goal was to develop a parametric model of the construction system that allows its customization and digital production. In Material, the investigation focused on material properties, detailing of the wall and adequacy of the material solution to the context. Moreover, the assembly process was also conceived. Finally, in Production, the solutions were prototyped to verify how the selected fabrication process - a 3 axis CNC router -, interacts with the materials and constrains the proposed solutions, as well as to test the envisioned assembly process. These three areas are intricately connected yet it isn't possible to map the complexity of relations between them. Hence a top-down design process was adopted to develop the Cork re-Wall parametric partition wall. To overcome the risk of prioritizing preliminary design decisions, conditioning material and fabrication solutions, three cycles of design to production were performed. 3-D point cloud scanning was initially considered for acquiring accurate digital models of the buildings, thus creating a full digital pipeline. Eventually it was dropped because it would condition the application of the wall to what is still a relatively new and expensive technology.

\section{Results}

On the first cycle, a subdivision grammar, that follows up on Sass's Wood Frame Grammar (Sass, 2005)(WFG), was used as a starting point to troubleshoot the nature of corner conditions, wall ends and walls panels. Three different solutions for wall panels were designed, detailed and prototyped: wood frame - cork infill panels; sandwich panels with cork infill and plasterboard/OSB sheet layers; sandwich honeycomb cork infill panels with plasterboard/ OSB sheet layers. It was determined that ICB could not be used effectively for structural purposes and that it doesn't withstand small details both due to the production process and the cohesion of the aggregate. The wood frame solution proved to be the best of the three, both in terms of cost and fulfillment of the previously stated objectives. Assembly of the two sandwich cork solutions relied on a dovetail detail on the cork layer that proved difficult to assemble.

On the second cycle, the wood frame solution was revised both in terms of the detailing of the joints and the assembly process (Figure 4). Solutions for wall ends and corner were designed. A three layer infill composite panel of OSB, ICB and plywood was introduced to improve the in-plane behavior of the wall and reduce its thickness. The studs were also reduced to meet the previous objective. The first parametric models were tried out in Grasshopper parametric modeling environment. Several algorithms were devolved in C\# to subdivide walls into structure and panels according to the design rules of the partition wall (Figure 5). The wood frame structure and the infill composite panels were prototyped and 
assembled. It was concluded that several modifications were needed: increasing the thickness of the structure, reducing the number of layers of the panel to only two to reduce cost
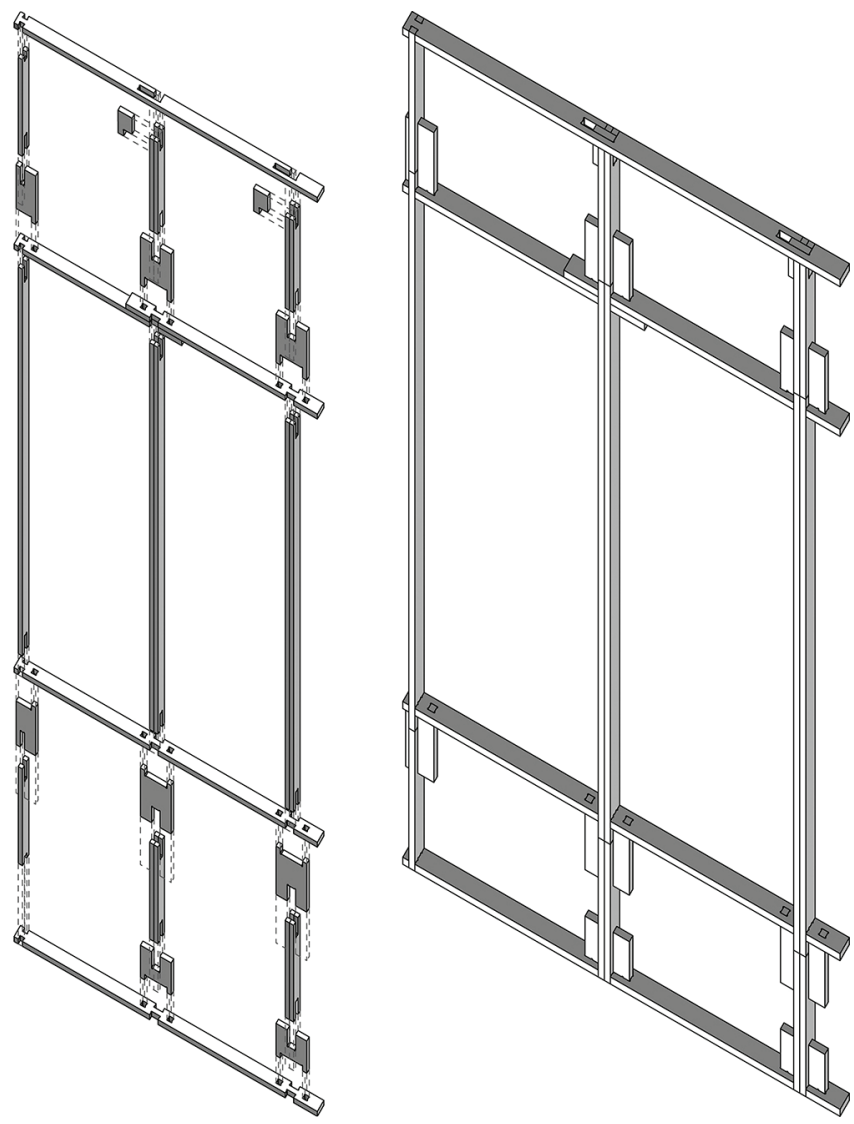

Figure 4: Structure parts and assembly sequence.
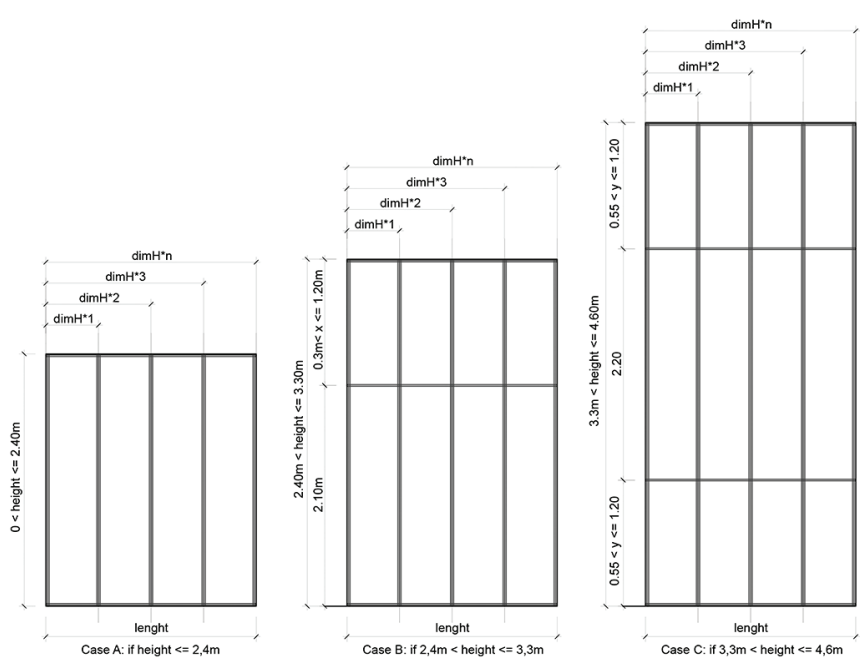

Figure 5: Design rules for wall subdivision into structural members. and improve the assembly process.

Design

Cork Re-Wall parametric wall is composed of a wood frame structure cut out of OSB panels and composite panels of ICB and plywood. The composite panels perform both finishing and bracing functions of the wall structure. The finish can be either ICB, plywood or a customizable pattern of cork and plywood (Figure 7). The design and dimensioning of the wall components was conditioned by the standard dimensions of ICB boards (1000x500mm). The on-center distances of the studs are half the length of the panels and the paneling of the structure is done in a stretcher like pattern. Standard dimensions of OSB panels have also conditioned the length of the studs and blocking. The wall can be configured to any dimension, yet the maximum height of the wall was set to 4,60 $\mathrm{m}$. The vertical subdivision of the studs is of necessity, both for structural reinforcement and to accommodate the maximum length of standard OSB panels. Three cases of vertical subdivision were defined to strike a balance between cost and structural efficiency (Figure 5). Double vertical studs, simple wall studs, ceiling and sole plates are common to all

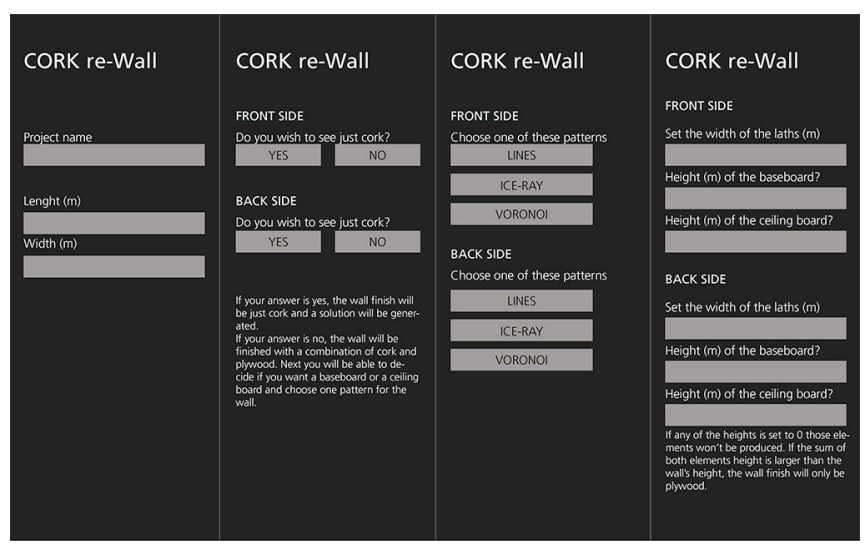

cases, with blockings being added as the height increases. Figure 6: Program interface sequence

The parametric model was developed with two purposes in mind: to simulate the system behavior and optimize it, as well as to provide an interface for design customization and digital fabrication by an end user be it a client or an architect. It is both a design and an evaluation system. For this reason the parametric model produces accurate 3D geometry that can be used for visual inspection, for simulation purposes and to extract 2D paths for production. The model was conceived as an interactive program that poses a sequence of questions to the user (Figure 6): what is the length and height of the wall, what is the desired finishing, whether there are baseboards or coving and lastly the selection and customization of the 
pattern. The provision of customizable height baseboards and coving is an important aspect of the adaptation to the context of old buildings, where the size of these existing elements can vary widely. Besides this aesthetic function, coving can also be used to absorb the height of suspended ceilings that would otherwise conceal part of the customizable pattern. Different finishes can be selected for both sides of the wall but if the user choses to have cork or plywood as finishing, a composite panel solution that is optimized for cost and structural efficiency is generated. A choice of three patterns that can be customized is provided. Those are a line pattern, an Ice-Ray lattice pattern and a Voronoi pattern. The line pattern consists of a sequence of horizontal laths whose width and number can be controlled within a set range. Iceray pattern is a latticework generated by an algorithm that allows the control of thickness and maximum angle of the laths. The possibility to enter a number is also provided. The Voronoi pattern shares the same options of the later pattern but without the angle control.

When the wall is configured the program generates 2D line drawings of the structural elements organized in standard OSB panels, and 2D paths for ICB milling and plywood cutting. These drawings can be sent to production for cutting and assembly. It also generates spreadsheets with material quantities and a cost estimate. The program was outlined in Grasshopper parametric environment as a proof of concept but it can be transformed into a website or an application that is directly linked with a manufacturer that produces and delivers the parts to the customer. These can be either assembled by the client or by a team.

\section{Material}

The structure members are cut out of a standard OSB $15 \mathrm{~mm}$ panel with a $\mathrm{CNC}$ router. The connections are friction fit and the assembly is performed manually with a rubber mallet. This process bears several similarities with Sass Wood Frame Grammar (2005), however it's novelty lies in the design of the joints, the dimensioning of the members and the use of several materials to address different performance needs of the wall. The nature of existing floors, ceilings and walls of refurbished buildings lies outside the control of this process, so friction fit joints between the wall and the supports aren't possible. Instead, ceiling and sole plates with a $20 \mathrm{~mm}$ ICB layer are fastened with screws to the ceiling and floor slabs. The same detail is used to connect end studs to supporting walls. The use of cork layers between the wall structure and support serves three purposes: to dampen percussion sound, to absorb vertical loads that might be transmitted by the deflection of the ceiling slabs, to absorb construction planarity deficiencies in the supports. The structure parts are numbered and the assembly process proceeds from the floor up and from one

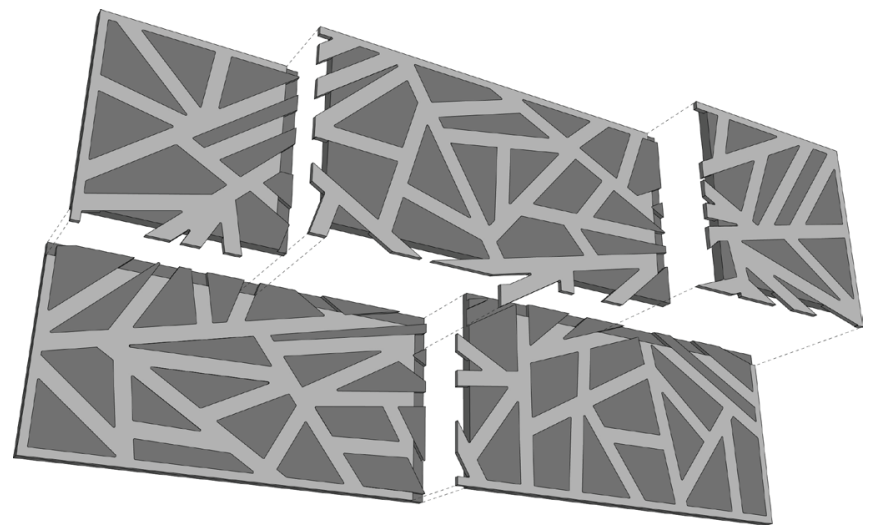

side to the other.

Figure 7: Composite panels and assembly sequence

The composite panels are made of $30 \mathrm{~mm}$ ICB boards from which the $12 \mathrm{~mm}$ plywood patterns are milled (Figure 7). The plywood patterns are cut from $12 \mathrm{~mm}$ standard panels into $1000 \times 500 \mathrm{~mm}$ sized shapes, are glued to ICB boards in the workshop and transported on-site to be fastened to the structure. To provide a joint between panels and improve the wall's structural performance, plywood patterns are displaced by $35 \mathrm{~mm}$ both vertically and horizontally in relation to the ICB boards. This provides an overlap of the next composite panel plywood with the previous composite panel's cork. This overlapping area is coincident with the double studs, allowing for both panels to fasten to the structure. The assembly sequence of the panels is the same as the structure.

A wall was generated for each of the three case studies, replacing new walls that each of the architecture projects foresees (Figure 8). The process of solution generation was evaluated for its fitness to the goals set by the project architects and for its adequacy in replacing the solutions defined in working drawings. 3D renderings were also produced to

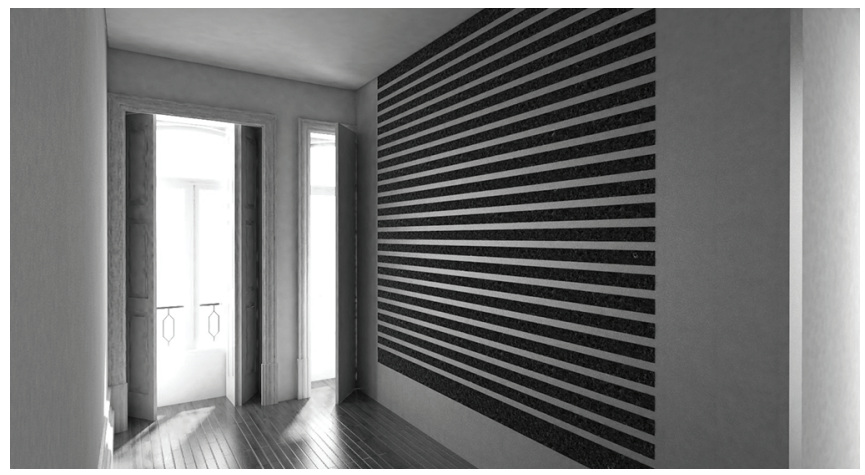

Figure 8: Rendering of room divided with a generated wall with a line pattern and baseboard. 
allow for visual evaluation.

A comparison between a typical Cork Re-Wall partition and several LST partition walls was performed (Table 10) in order to understand if the partition wall design maintained the relative EC and EE advantages its materials display (Table 3). A wall with $3,3 \mathrm{~m}$ height and $6 \mathrm{~m}$ long was selected as a case study. Four different solutions for LST partitions were considered: the first with $46 \mathrm{~mm}$ studs and double sheets of plasterboard, two with $70 \mathrm{~mm}$ studs, single or double sheets and the last one with $90 \mathrm{~mm}$ studs with one sheet of plasterboard. The EE and EC material typical values are Cradle to Gate and thus do not include cold lamination of galvanized steel coil into profiles and all the materials and energy spent in the assembly of LST partitions with the exception of mineral wool and plasterboards. The same is true for Cork Re-Wall parametric partition which EE and EC values don't include the processing of plywood, OSB and ICB standard boards.

Cork Re-Wall global weighted Embodied Energy per square meter was $87 \%$ to $131 \%$ smaller than LST walls, and EC values were $90 \%$ to $160 \%$ smaller.

\section{Production}

Several cycles of digital fabrication were performed to test the assembly process of the structure and the composite panels. This section presents the design, fabrication and assembly of

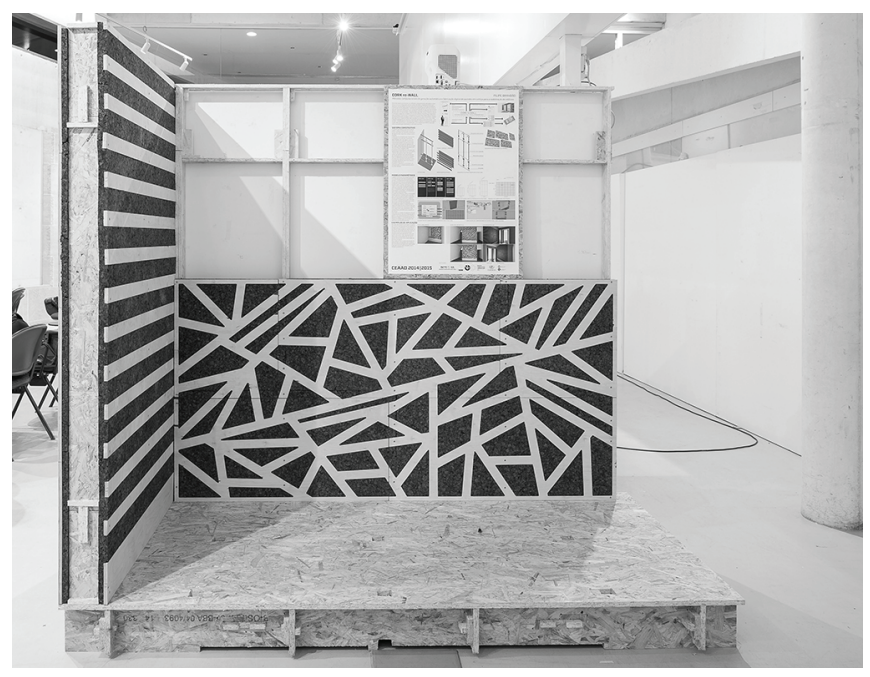

two walls for the CEAAD course final exhibition (Figure 9). Figure 9: CEAAD final exhibition stand.

The designated area for the stand was 2,16 $\mathrm{m}$ in length, $1 \mathrm{~m}$ wide and 2,05 $\mathrm{m}$ high. There was a wall defining the area on one side along its length. It was decided to build an $\mathrm{L}$ shaped wall with the long side against the existing wall, as there was no ceiling to connect the walls to, and it wasn't possible to fasten anything to the only existing wall. A wooden plinth was constructed to provide a base to fasten the walls to.

The parametric model only generates single walls so far, so two independent walls were generated with the required length and thickness, the shortest wall with a structure thickness of $100 \mathrm{~mm}$ and the other with $70 \mathrm{~mm}$. A bigger height than needed was used to generate the walls in order to show and test the complete set of connections of the wall. Generating a wall with the exact height required would have produced a structure with studs, sole and ceiling plates only. The geometry was then exported to Rhino modeling environment for scaling. A new corner connection was designed to join the two walls, which is not yet implemented in the parametric model. Composite panels were produced for both sides of the shortest wall, with different patterns on each side, and a panel with $1 \mathrm{~m}$ high and $2 \mathrm{~m}$ long for the longest wall, in order to reveal part of the structure. The exact final dimensions were used to generate the composite panels which were then exported to $2 \mathrm{D}$ files ready for production. The production took place at Vitruvius FABLAB-IUL, on a CNC 3-axis milling machine.

\begin{tabular}{|l|c|c|c|c|}
\cline { 2 - 5 } \multicolumn{1}{c|}{} & \begin{tabular}{c}
$\mathrm{U}$ \\
{$\left[\mathrm{W} / \mathrm{m}^{2}\right.$.} \\
\multicolumn{1}{c|}{$\cdot \mathrm{C}]$}
\end{tabular} & $\begin{array}{c}\mathrm{mTSU} \\
{\left[\mathrm{J} / \mathrm{m}^{2} . \mathrm{C}\right] \mathrm{x}} \\
10^{3}\end{array}$ & $\begin{array}{c}\mathrm{EEs} \\
{\left[\mathrm{MJ} / \mathrm{m}^{2}\right]}\end{array}$ & $\begin{array}{c}\mathrm{ECs} \\
{[\mathrm{KgCo} 2 \mathrm{e} /} \\
\left.\mathrm{m}^{2}\right]\end{array}$ \\
\hline $\begin{array}{l}\text { Cork re- } \\
\text { Wall }\end{array}$ & 0,59 & 13 & 153 & 10 \\
\hline $\begin{array}{l}\text { LST } \\
96 / 600 \\
(46)\end{array}$ & 0,74 & 18 & 354 & 22 \\
\hline $\begin{array}{l}\text { LST } \\
100 / 400 \\
(70)\end{array}$ & 0,77 & 12 & 306 & 20 \\
\hline $\begin{array}{l}\text { LST } \\
120 / 400 \\
(70)\end{array}$ & 0,67 & 19 & 414 & 26 \\
\hline $\begin{array}{l}\text { LST } \\
120 / 600 \\
(90)\end{array}$ & 0,64 & 12 & 286 & 19 \\
\hline
\end{tabular}

Table 10: Global weighted values per sqm of wall.

\section{Conclusions}

The results presented in this paper showed Cork ReWall partition wall is a more eco-friendly solution. It can be reused and it is built with renewable and reusable materials that contain lower levels of embedded energy and carbon. The parametric model grants the possibility to produce solutions that are adapted to specific renovation contexts, in terms of design and dimensioning, reducing waste, assembly complexity and time. The composite panels provide structural performance improvement while its detail reduces sound transmission by introducing a layer of ICB between the plywood pattern and the structural members. The proposed digital process can circumvent the loss of workmanship and provide customized solutions without increasing design or production cost. Moreover, the parametric system provides the client the opportunity to have a direct role in designing the solution, with both visual and quantitative feedback. 
Nonetheless, not all patterns are equally economical in terms of the use of plywood. A line pattern is far more economical that an Ice-Ray or Voronoi pattern. Further work is needed to improve on the use of plywood and also to implement solutions for a wider range of wall shapes. It is also necessary to expand the life cycle analysis of the system to include the $\mathrm{CNC}$ fabrication stage.

The Cork Re-Wall design-based research demonstrates the advantages of a close relationship between the construction industry and the academia.

\section{References}

Blikstein, P. (2013). Digital fabrication and "making"in education: The democratization of invention. FabLabs: of Machines, Makers and Inventors. Retrieved from http:// www.academia.edu/download/30555959/Blikstein-2013Making_The_Democratization_of_Invention.pdf

Bugalho, M. N., Caldeira, M. C., Pereira, J. S., Aronson, J., \& Pausas, J. G. (2011). Mediterranean cork oak savannas require human use to sustain biodiversity and ecosystem services. Frontiers in Ecology and the Environment, 9(5), 278-286. http://doi.org/10.1890/100084

Clayton, M. (1995). Connecting Digital Tools. In cumincad. architexturez.net (p. 1988). Retrieved from http://cumincad. architexturez.net/system/files/pdf/acadia03_039.content. pdf

Fortes, M. A., Rosa, M. E., \& Pereira, H. (Eds.). (2003). A Cortiça. Lisbon: IST Press.

Freitas, V. P. de. (2012). Manual de apoio ao projecto de reabilitação de edifícios antigos. (V. P. de Freitas, Ed.). Porto: Ordem dos Engenheiros da Região Norte.

Gil, L. (1998). Cortiça. Produção, Tecnologia e Aplicação. Lisbon: INETI.

Gil, L. (2014). Cork: a strategic material. Frontiers in Chemistry, 2(April), 16. http://doi.org/10.3389/fchem.2014.00016

Gil, L. M. C. C. (1996). Densification of black agglomerate cork boards and study of densified agglomerates. Wood Science and Technology, 30(3). http://doi.org/10.1007/BF00231635

Gil, L., Marreiros, N., \& Silva, P. (2011). Insulation corkboard carbon content and CO 2 equivalent, 23, 42-43.

Gil, L., \& Silva, P. (2011). Thermal Behaviour of ICB obtained from Demolitions. In WASTES: Solutions, Treatments and
Opportunities. Guimarães.

Hammond, P. G., \& Jones, C. (2006). Inventory of Carbon \& Energy (ICE). Mechanical Engineering, 1-49. http://doi. org/10.1680/ener.2008.161.2.87

Kieran, S., \& Timberlake, J. (2003). Refabricating architecture. New York: McGraw-Hill. Retrieved from http://www. magisterarq.cl/fileadmin/docs/trayectoria_trabajos/ Arquitectura_e_industria/61_Refabricating_Processes_ MACARENABURDILES.pdf

Lakreb, N., Bezzazi, B., \& Pereira, H. (2015). Mechanical strength properties of innovative sandwich panels with expanded cork agglomerates. European Journal of Wood and Wood Products, (Pereira 1992). http://doi.org/10.1007/ s00107-015-0908-y

Naboni, R., \& Paoletti, I. (2015). Advanced Customization in Architectural Design and Construction. Springer. London: Springer. http://doi.org/10.1007/978-3-319-04423-1

Pereira, H. (2007). Cork: Biology, Production and Uses. Amesterdam: Elsevier.

Sass, L. (2005). Wood Frame Grammar : CAD Scripting a Wood Frame House, 1-10.

Sousa, J. P. (2010). From Digital to Material: Rethinking Cork in Architecture through the use of CAD/CAM Technologies. IST, Technical University of Lisbon.

Varela, P. A., Paio, A., \& Sousa, J. P. (2014). The cork vault pavilion: A Design Research through Practice. In F. Madeo and F. Novi (Ed.), Architectural Research through to Practice: 48th International Conference of the Architectural Science Association (pp. 395-404). Genova: The Architectural Science Association.

\section{Acknowledgments}

We thank the material support provided by AMORIM Isolamentos SA., and the scientific and technological support of the VITRUVIUS FABLAB-IUL, at the Lisbon University Institute (ISCTE-IUL), and the Digital Fabrication Lab (DFL) at Faculty of Architecture, University of Porto. This research was developed during the Advanced Studies Course in Digital Architecture (CEAAD) a joint initiative between ISCTE-IUL and FAUP. 